\title{
EFFECTIVENESS AND SAFETY ASSESSMENT OF FIXED DOSE COMBINATION OF NON- STEROIDAL ANTIINFLAMMATORY DRUGS PRESCRIBED FOR ORTHOPEDIC PATIENTS
}

\author{
NILAY SOLANKI ${ }^{*}$, ALPA GOR ${ }^{2}$, BIRAJ PARMAR ${ }^{3}$
}

${ }^{1,3}$ Ramanbhai Patel College of Pharmacy, Department of Pharmacology, CHARUSAT, Changa, Gujarat-388421, 2Pramukh Swami Medical College, Karamsad, Gujarat

Email: nilaysolanki.ph@charusat.ac.in

Received: 12 Sep 2019, Revised and Accepted: 17 Dec 2019

\begin{abstract}
Objective: Many Fix Dose Combinations (FDCs) being introduced in India are usually irrational. The most pressing concern with irrational FDCs is that they expose patients to unnecessary risk of adverse drug reactions, for instance, pediatric formulations of nimesulide+paracetamol. Despite their wide clinical use, their gastro-intestinal toxicity is a major limitation. The aim of the present work was to evaluate the efficacy and safety of FDCs in non-steroidal anti-inflammatory drugs in the orthopedic department at a tertiary care teaching hospital. To study the effectiveness and safety parameters of fixed-dose combinations of Non-Steroidal Anti-inflammatory Drugs.
\end{abstract}

Methods: This prospective, observational study was conducted among 150 out-patients of the orthopedic ward over a period of July 2013 to December 2013(Each combination with 50 patients). Three fixed-dose combinations utilized were paracetamol+diclofenac, paracetamol+ibuprofen and paracetamol+nimesulide. The effectiveness was analyzed by using Visual Analogue Scale (VAS) and Disease Activity Scale (DAS) and the safety criteria were analyzed by using the WHO probability scale and Naranjo scale. 150 orthopedic patients attending Out Patient Department were included. 50 participants for each of the combinations of fixed-dose combination (FDCs) of NSAIDs.

Results: Out of 150 patients 33 patients developed adverse effects, and 17(51.51\%) adverse effects due to the combination of Paracetmol+Nimuselide, $11(33.34 \%)$ adverse effects due to the Paracetamol+Ibuprofen and 5 (15.15\%) were due to the combination of Paracetamol+Diclofenac. The maximum effectiveness $(3.55 \pm 0.208)$ showed in the combination of paracetamol+diclofenac compared to the other two combinations.

Conclusion: It was concluded from this study that the effectiveness and safety profile of PCM+DICLO is better than the other two FDCs.

Keywords: Fix Dose Combinations, Paracetamol+diclofenac, Naranjo scale and WHO probability Scale

(C) 2020 The Authors. Published by Innovare Academic Sciences Pvt Ltd. This is an open-access article under the CC BY license (http://creativecommons.org/licenses/by/4.0/) DOI: http://dx.doi.org/10.22159/ijpps.2020v12i2.35666. Journal homepage: https://innovareacademics.in/journals/index.php/ijpps

\section{INTRODUCTION}

Non-steroidal anti-inflammatory drugs (NSAIDs) are one of the most commonly prescribed drugs in the world for their analgesic, antipyretic and anti-inflammatory properties. Presently, several varieties of fixed-dose combinations (FDCs) of NSAIDs are available over the counter and are being prescribed too [1]. FDCs are reviewed by regulating agencies (such as the Food and Drug Administration in the United States), the active ingredients used in the FDCs are unlikely to exhibit adverse drug interaction with each other [2]. However, FDCs may interact with other drugs that a patient is taking, so the usual medical and pharmaceutical precautions against drug-drug interactions [3]. FDCs are highly popular in the Indian pharmaceutical market and have been particularly flourishing in the last few years [4]. Many FDCs being introduced in India are usually irrational. The most pressing concern with irrational FDCs is that they expose patients to unnecessary risk of adverse drug reactions, for instance, pediatric formulations of nimesulide+paracetamol. Nimesulide alone is more antipyretic than paracetamol, more anti-inflammatory than aspirin, and equivalent in analgesia to any of the NSAIDS alone, so efficacy gains are unlikely with added paracetamol. However, the patients may be subject to increased hepatotoxic effects from the combination. With this background, the aim of the present study was to evaluate the efficacy and safety of FDCs (Paracetmol+Nimuselide, Paracetamol+Ibuprofen, Paracetamol+Diclofenac) in non-steroidal anti-inflammatory drugs in the orthopedic department at Karam said.

\section{MATERIALS AND METHODS}

\section{Methodology}

The prospective observational study was conducted at Shree Krishna Hospital from July 2013 to December 2013. Ethical approval was obtained from the institutional ethics committee Karamsad.
Overview of methodology

\begin{tabular}{|c|c|}
\hline \multicolumn{2}{|c|}{ Patients were confirmed by physician } \\
\hline Orthopedic Out Patients Department were considered for study \\
\hline Explaination of Informed consent were given to patients \\
\hline Type of Combination (FDCs) prescribed by physician Were noted down \\
\hline
\end{tabular}

Chart of an overview of the methodology

Inclusion criteria: Both genders with the age of above $18 \mathrm{y}$ receiving oral formulation of NSAIDs, Patients with All types of joint pain were included in the study.

Exclusion criteria: Paediatric, with liver disease, CVS disease, GI disease, Patients who are receiving Topical drugs.

Sample size: 150 orthopedic patients, attending the medicine OutPatient department were included.

The data were analysed by using Microsoft Excel and an unpaired ttest was applied to check the effectiveness of three fixed-dose combinations of NSAIDs. 


\section{RESULTS}

In the present study out of 150 participants one hundred patients were male $(66.66 \%)$ and fifty $(33.34 \%)$ females. In the present study Paracetamol+Nimesulide (PCM+NIM), Paracetamol+ Diclofenac
(PCM+DICLO) and Paracetamol+Ibuprofen (PCM+IBU) FDCs were evaluated for its effectiveness and safety criteria. Maximum combinations were found of all three FDCs in the age range of 20-40 y in male participants and in females from 20 $60 \mathrm{y}$ (table 1).

Table 1: Utilization of FDCs with gender and age distribution

\begin{tabular}{|c|c|c|c|c|c|c|}
\hline \multirow[t]{2}{*}{ Gender } & \multirow[t]{2}{*}{ Age group } & \multirow[t]{2}{*}{ No of patients } & \multicolumn{3}{|c|}{ Combination } & \multirow[t]{2}{*}{ Total } \\
\hline & & & PCM+NIM & PCM+DICLO & PCM+IBU & \\
\hline MALE & $20-30$ & $30(30 \%)$ & 10 & 11 & 9 & 30 \\
\hline \multirow{3}{*}{$(n-100)$} & $31-40$ & $40(40 \%)$ & 14 & 13 & 13 & 40 \\
\hline & $41-50$ & $20(20 \%)$ & 8 & 6 & 6 & 20 \\
\hline & $51-60$ & $10(10 \%)$ & 2 & 3 & 5 & 10 \\
\hline Female & $20-30$ & $12(24 \%)$ & 3 & 4 & 5 & 12 \\
\hline \multirow[t]{3}{*}{$(n-50)$} & $31-40$ & $8(16 \%)$ & 1 & 4 & 3 & 8 \\
\hline & $41-50$ & $15(30 \%)$ & 6 & 4 & 5 & 15 \\
\hline & $51-60$ & $15(30 \%)$ & 5 & 6 & 3 & 15 \\
\hline Total & & & 50 & 50 & 50 & 150 \\
\hline
\end{tabular}

Total 77 (51.33\%) patients had suffered from orthopedic conditions like trauma, tissue injury stains, and more than $50 \%$ patients were recorded with single morbidity (table 2).

Table 2: Orthopedic patients with comorbidities

\begin{tabular}{lll}
\hline Other comorbid conditions & No of patients $(\mathbf{N}=\mathbf{1 5 0})$ & \% \\
\hline Diabetes & 37 & $24.66 \%$ \\
Hypertension & 11 & $7.33 \%$ \\
Diabetes+Hypertension & 17 & $11.34 \%$ \\
COPD & 7 & $4.6 \%$ \\
PCOD & 1 & $0.66 \%$ \\
NO COMORBIDITIES & 77 & $51.33 \%$ \\
TOTAL & 150 & \\
\hline
\end{tabular}

In our study, the effectiveness scale of DAS was better in the case of PCM+DICLO and PCM+IBU compared to PCM+NIM.

Patients treated with all FDCs and the disease activity score was calculated (fig. 1) and the maximum effectiveness $2.91 \pm 0.45$ (mean \pm SEM) was shown with the combination of PCM+DICLO compared to the other two combinations.

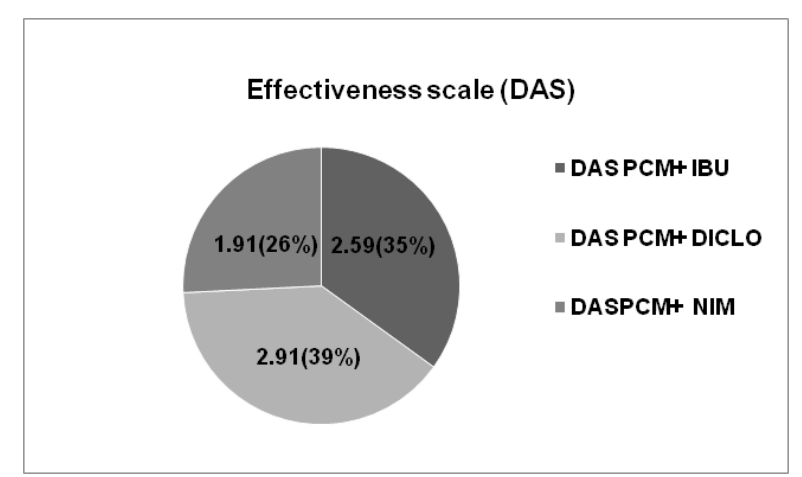

Fig. 1: Effectiveness scale (DAS), the maximum effectiveness according to visual analogue scale score is $3.55 \pm 0.20$ showed in the combination of PCM+DICLO compared to the other two combinations (fig. 2)

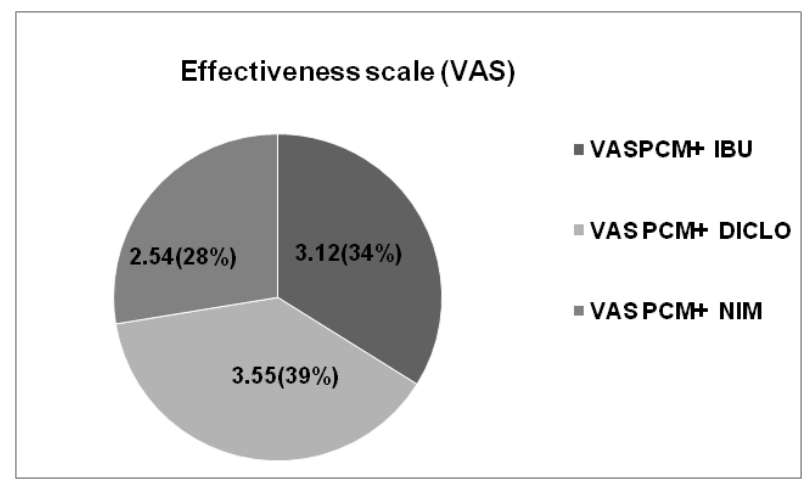

Fig. 2: Effectiveness scale (VAS) 
In our study, 33 patients developed adverse effect out of 150, and out of this $17(51.51 \%)$ adverse effects were due to the combination of PCM+NIM, $11(33.34 \%)$ adverse effects due to the PCM+IBU and 5 $(15.15 \%)$ adverse effects due to the combination of PCM+DICLO (table 3).

Causality assessment has been done as per WHO probability scale and Naranjo scale, According to WHO scale 15 adverse effects were possible in nature and remaining 8, 7 and 3 adverse effects were doubtful, probable and conditional in nature, According to Naranjo scale 18 adverse effects were possible in nature and remaining 2 and 11 adverse effects were doubtful and probable in nature. In this prospective observational study suggested that FDCs use was higher in male patients may be the orthopedic condition was highly prevalent in male patients.

Table 3: Adverse effects in prescribed FDCs

\begin{tabular}{llllll}
\hline FDCs & Adverse effects & & & & \\
\cline { 2 - 6 } & Vomiting & Urticaria & Constipation & GI Upset & Total \\
\hline PCM+NIM & 5 & 6 & 4 & 2 & 17 \\
PCM+IBU & 4 & 2 & 3 & 2 & 11 \\
PCM+DICL & 2 & 0 & 2 & 1 & 51.51 \\
Total & 11 & 8 & 9 & 5 & 3.34 \\
\hline
\end{tabular}

Table 4: Causality assessment of adverse drug reaction

\begin{tabular}{lll}
\hline ADR & WHO (\%) & Naranjo (\%) \\
\hline Certain & 0 & 0 \\
Probable & $7(21 \%)$ & $4(12.12 \%)$ \\
Possible & $15(45.45 \%)$ & $18(54.54 \%)$ \\
Unlikely/Doubtful & $8(24.24 \%)$ & $11(33.33 \%)$ \\
Conditional & $3(9.09 \%)$ & 0 \\
Total & $33(100 \%)$ & $33(100 \%)$ \\
\hline
\end{tabular}

Age group between 31-40 y was more prevalent for use of FDCs than the patients presented with single comorbidities. Comorbidities like diabetes, hypertension and COPD were common in this study. Out of these combinations, it's showed that PCM+DICLO was more effective than PCM+NIM and PCM+IBU. Side effects were more prevalent with the use of PCM+NIM than PCM+DICLO and PCM+IBU.

\section{DISCUSSION}

WHO has suggested specific pain therapy protocols including simple analgesics to be selected at the first instance where any other NSAIDs do not respond well. In India currently, there is huge market of paracetamol and diclofenac combination [11]. This study was conducted with the objective of effectiveness and safety assessment of fixed-dose combinations of non-steroidal anti-inflammatory drugs. In this study, three different FDCs were used for evaluation as PCM+DICLO, PCM+IBU, and PCM+NIM. Here selected FDCs are most frequently used in therapy for orthopedic conditions.

In present study out of 150 patients Comorbidity observed as $37(24.66 \%)$ patients with diabetes, $17(11.34 \%)$ patients with diabetes and hypertension, 11(7.33\%) patients with hypertension only, $7(4.6 \%)$ patients having COPD and $1(0.66 \%)$ patients with PCOD. The previous study showed that maximum patients observed with comorbidity of Diabetes (29\%) while remaining were COPD, renal disease, hypertension [6]. Another study observed maximum patients with comorbidity of diabetes (32\%) along with blood pressure, COPD, renal disease, heartburn, headache, urinary disease [7], which supported our study results.

Present work showed the effectiveness of DAS in a better way for PCM+DICLO and PCM+IBU compared to PCM+NIM. In the study conducted by Merryet AF et al., observed DAS interpreted the maximum effect of the drug $(3.55 \pm 0.37)$ from a combination of Paracetamol+Ketoralac than of Paracetamol+Oxaprozin and Paracetamol+Ibuprofen. In this study, Paracetamol+Ketoralac is more effective than the other two types of combination [8]. In other studies by Spofford CM et al. DAS interpreted the maximum effect of drug $(2.79 \pm 0.27)$ from a combination of Paracetamol+Diclofenac than the other two combinations of Paracetamol+Ibuprofen and Paracetamol+Tolmetin, which was supporting our study results. In one study the Paracetamol+Diclofenac is more effective than other two types of combination also supporting our study results [9]. Anderson JK et al. showed DAS which interpreted the maximum effect of the drug $(2.97 \pm 0.17)$ from a combination of
Paracetamol+Ketoralac than their two combinations of Paracetamol+Oxaprozin and Paracetamol+Ibuprofen. In this study, Paracetamol+Ketoralac is more effective than the other two types of combination [10]. Williams DL et al. interpreted the maximum effect of the drug $(2.67 \pm 0.11)$ from a combination of Paracetamol+ Diclofenac than their two combinations of Paracetamol+Ibuprofen and Paracetamol+Tolmetin for DAS. In this study, Paracetamol+Diclofenac is more effective than the other two types of combination [11]. The study conducted by a group of scientists showed significant pain control in the diclofenac group, whereas the duration of action is significantly increased in hydroxychloroquine [13]. Here It was seen that the incidence of gastric ulcers more common in the diclofenac group when compared to the hydroxychloroquine group. In another study, it was observed that Diclofenac sodium tablets, diclofenac sodium injection, oral paracetamol, and oral ibuprofen were prescribed as $45.1 \%, 27.5 \%$, $15.9 \%$, and $11.5 \%$, respectively [14]

Two major scales (WHO, Naranjo scale) were used to assess the causality for adverse effects (AE). The major $\mathrm{AE}$ observed were vomiting, urticaria, constipation, and GI upset. Possible scale observed very high in the case of the WHO and Naranjo scale in our study. Out of 150 patients, 33 patients develop adverse effects, and $51.51 \%$ adverse effects due to the combination of $\mathrm{PCM}+\mathrm{NIM}, 33.34 \%$ adverse effects due to the PCM+IBU and $15.15 \%$ adverse effects due to the combination of PCM+DICLO. One scientific study showed that PCM+NIM was the culprit in causing ADRs in $60 \%$ and PCM+DICLO was in $40 \%$ of the participants. GI-related adverse reaction observed in 28 participants. It was found that eighty percent of the adverse reaction was possible in nature [12], which supported our study results.

\section{CONCLUSION}

The present study concluded that the effectiveness profile of PCM+DICLO was better than the other two FDCs (PCM+NIM and $\mathrm{PCM}+\mathrm{IBU}$ ) in the major orthopedic condition by observing VAS and DAS. It was also concluded that the Safety profile of PCM+DICLO was better than the other two FDCs prescribed in the major orthopedic conditions by observing Naranjo scale and WHO probability scale.

\section{ACKNOWLEDGMENT}

Authors are thankful to Shree Krishna Hospital, Karamsad for providing the facility for the research work and also too Ramanbhai Patel College of Pharmacy for project-related help. 


\section{FUNDING}

Nil

\section{AUTHORS CONTRIBUTIONS}

Conceived and designed the study: Nilay Solanki, Alpa Gor, Biraj Parmar

Contributed materials/analysis tools: Nilay Solanki, Alpa Gor, Biraj Parmar

Manuscript preparation and correction and Correspondence: Nilay Solanki, Alpa Gor

\section{CONFLICT OF INTERESTS}

Declared none

\section{REFERENCES}

1. Shahani S, Nerleker S. Adverse drug reactions in dermatology and a growing need for pharmacovigilance. J Pharmacovig Drug Saf 2009;6:35-7.

2. Gor AP, Saksena M. Adverse drug reactions of non-steroidal anti-inflammatory drugs in orthopedic patients. J Pharmacol Pharmacother 2011;2:26-9.

3. Tsoukas C, Eyster ME, Shingo S. Evaluation of the efficacy and safety of etoricoxib in the treatment of hemophilic arthropathy. Blood 2006;107:1785-90.

4. Raghavendra B, Ullal SD, Kamath R. Trends in prescribing gastroprotective agents with non-steroidal anti-inflammatory drugs in an orthopaedic outpatient unit of a tertiary care hospital. J Clin Diagn Res 2009;3:1553-6.

5. Aletaha D, Smolen J. The simplified disease activity index (SDAI) and the clinical disease activity index (CDAI) a review of their usefulness and validity in rheumatoid arthritis. Clin Exp Rheumatol 2005;23:100-8

6. Sharma T, Dhasmana SC. Prescribing pattern of NSAIDs in orthopaedic OPD of a tertiary care teaching hospital in Uttaranchal. JK Science 2006;8:160-2.

7. Venkatachalam S, Bhat R. ADR monitoring of NSAIDs among the in-patients of the orthopaedic ward in a tertiary care center: a prospective observational study. J Clin Diagn Res 2012;6:42-6.

8. Shankar PR, Pai R, Dubey AK. Prescribing patterns in the outpatient department in a teaching hospital in Pokhara, western Nepal. Kathmandu University Med J 2007;5:16-21.

9. Uhlig T, Kvien TK, Pincus T. Test-retest reliability of disease activity core set measures and indices in rheumatoid arthritis. Ann Rheum Dis 2009;68:972-5.

10. Radovits BJ, Fransen J, van Riel PL. Influence of age and gender on the 28-joint disease activity score (DAS28) in rheumatoid arthritis. Ann Rheum Dis 2008;67:1127-31.

11. Yadav P, Kanase V, Lacchiramka P. Drug utilization trends in ENT outpatient department in a teaching hospital. Int J Pharm Biol Sci 2010;1:153-60.

12. Gor AP, Shah BK. Evaluation of prescribing pattern and adverse effects of fixed-dose combination of non-steroidal antiinflammatory drugs. Int J Basic Clin Pharmacol 2016;5:102933.

13. Praveen D, Ranadheer C, Rujaswini T. A prospective observational study on safety and efficacy of Hydroxychloroquine against diclofenac in osteoarthritis. Asian J Pharm Clin Res 2018;11:95-7.

14. Kulkarni M, Patil A. Drug utilization study in the orthopedics outpatient department of a tertiary care hospital in Maharashtra. Asian J Pharm Clin Res 2018;7:224-6. 